\title{
RELATIVE VALIDITY OF SHORT QUESTIONNAIRES TO ASSESS MEDITERRANEAN DIET OR LOW-FAT DIET ADHERENCE
}

\author{
K. Miura', T.R. Entwistle', J.E. Fildes ${ }^{2,3}$, A.C. Green ${ }^{1,4}$
}

\begin{abstract}
Background: Short diet questionnaires can quickly identify dietary habits with minimal burden for users but they require validation for use in specific populations. Objective: To assess relative validity against a food frequency questionnaire (FFQ) of two short questionnaires to assess a Mediterranean diet and a low-fat diet, respectively, among organ transplant recipients as a part of a pilot study. Design: Cross-sectional validation study. Setting: Heart or lung transplant recipients completed two short dietary questionnaires and a full semi-quantitative FFQ as the reference methods, on 3 separate days. Participants: Sixteen heart $(\mathrm{n}=8)$ or lung $(\mathrm{n}=8)$ transplant recipients aged 16 years or more, at least 6-months post-transplant and clinically stable patients in Manchester, UK. Measurements: Two short dietary questionnaires to assess their Mediterranean diet and low-fat diet and a semiquantitative FFQ. Relative validity was assessed by comparing the scores derived from each short questionnaire with that of the FFQ. Agreement was assessed using the limits of agreement (LOA), and the agreement was expressed as a ratio of the score from the short dietary to the FFQ score with a ratio of 1.00 indicating perfect agreement. The agreement was formally tested by the two one-sided t-test procedure. Results: The mean agreement was 0.99 (95\% LOA 0.60-1.38) for the Mediterranean and 1.04 (95\% LOA 0.42-1.64) for the low-fat diet. The two one-sided t-test procedure showed the short questionnaires and the reference method were equivalent (Mediterranean diet overall $\mathrm{p}=0.004$; low-fat diet overall $\mathrm{p}<0.001$ ). Conclusions: Dietary habits to measure Mediterranean diet and a low-fat diet by short dietary questionnaires and full FFQ were comparable among organ transplant recipients.
\end{abstract}

Key words: Solid organ transplant recipients, intra-class correlation coefficient, limits of agreement.

\section{Introduction}

Since both a low-fat diet or a Mediterranean diet can reduce the risk of cardiovascular disease (CVD) in the general population (1-3), dietary interventions according to these regimes also offer a drug-free approach to lowering risk of CVD among groups at particularly high risk of CVD such as organ transplant recipients (4). In order to assess the effectiveness of these specific interventions in organ transplant recipients, however, dietary instruments are required that can reliably assess transplant patients' low fat or Mediterranean dietary intakes.

Traditionally, such dietary intakes have been assessed using detailed dietary intake methods such as food frequency questionnaires (FFQ) and 24-hour recall. While

1. Cancer and Population Studies Group, QIMR Berghofer Medical Research Institute, 300 Herston Road, Herston, Queensland, 4006 Australia; 2. The Transplant Centre, University Hospital of South Manchester, Manchester, M23 9LT, UK; 3. Manchester Collaborative Centre for Inflammation Research, University of Manchester, Manchester; 4. CRUK Manchester Institute and University of Manchester, Wilmslow Road, Manchester.

Corresponding Author: K Miura, Cancer and Population Studies Group, QIMR Berghofer Medical Research Institute, 300 Herston Road, Herston, Brisbane, Queensland, 4006 Australia. Email: Kyoko.Miura@qimrberghofer.edu.au

Received October 19, 2016

Accepted for publication December 13, 2016 these methods provide detailed food and nutrient intake, they are cumbersome for users; therefore, (delete and so) short dietary questionnaires are increasingly being used (5). Rather than providing accurate intakes, short dietary questionnaires rank users as having low or high intakes of relevant food groups and nutrients, equivalent with adhering or not adhering to the specified dietary pattern (6).

A number of short dietary questionnaires have been validated and successfully used in dietary intervention studies (6-8); however, they have been devised for specific populations without evidence of being transferable (9). We therefore sought to assess the validity of two brief questionnaires to assess dietary intakes in a group of organ transplant recipients according to a Mediterranean diet and a low fat diet, respectively compared with a traditional FFQ.

\section{Materials and methods}

This validation study was conducted as a part of a pilot study. Prior to the main study, randomly selected heart and lung transplant recipients at the University Hospital of South Manchester took part in 2013. Participants were identified through hospital records at the transplant 
outpatient clinic. Recruited patients were aged 16 years or more, clinically stable and at least 6-months post-transplant. They were asked to independently complete 3 questionnaires on 3 consecutive days: 1) a semi-quantitative FFQ, 2) a short Mediterranean diet questionnaire, and 3) a short low-fat diet questionnaire in that order. This study was approved by the NRES Committee North West (REC reference number 13/ NW/0310) and all participants provided written informed consent.

\section{Dietary assessment}

\section{Short Mediterranean diet questionnaire}

A one-page short questionnaire to assess Mediterranean diet was adapted from the validated questionnaire used in the Prevención con Dieta Mediterránea (PREDIMED) study $(6,10)$. It consists of a total of 14 questions that characterize key food groups commonly consumed as part of a traditional Mediterranean diet (12 questions about frequency of food consumption; two questions about food intake habits) (Table 1). Favorable responses (yes) were assigned a value of 1, and unfavorable responses (no) were assigned 0 . Answers summed to a total Mediterranean diet score ranging from 0 to 14 , with higher scores indicating greater adherence.

\section{Short dietary intake questionnaire: low-fat diet}

We similarly adapted the short low fat diet questionnaire to assess from the PREDIMED study (10). It contained consumption frequencies or serving size of seven food items (scored 0 to 2 with higher scores for favorable responses) and two items about habits relating to fat intake (scored 1 for yes , 0 for no) (Table 2). Resultant scores ranged from 0 to 16 with higher scores indicating greater adherence to a low-fat diet.

\section{Food frequency questionnaire}

Participants were also asked to complete a 183item semi-quantitative FFQ adapted from the US Nurses' Health Study and validated and updated to reflect Australian dietary habits $(11,12)$ with high reproducibility(13). Further updates were then made to reflect UK dietary choices (14). Consumption frequencies in the FFQ ranged from 'never' to ' $\geq 4$ times/ day'. Serving sizes were expressed either as standard measurements (i.e. one cup, one tablespoon, etc.) or in natural units (i.e. one slice, etc.). Additional questions collected information on trimming of visible fat from meat, and types of fats and oils used on foods. Responses were collated according to the food consumption patterns of each short dietary questionnaire and scores derived accordingly.

\section{Statistical analysis}

All dietary measures were handled as continuous variables and were all normally distributed. The agreement between the two dietary methods was also assessed using limits of agreement (LOA) (15). The difference (bias) was expressed as a ratio of the score from the short dietary to the FFQ score with a ratio of 1.00 indicating perfect agreement. The mean scores of the two methods and the mean score differences were displayed plotted using the Bland and Altman plot (95\% confidence limits were defined as the mean difference between the methods $\pm 1.96 \times$ standard deviation (SD), where SD was the SD of the differences between the two methods).

Adequate agreement between the short questionnaire and the reference method was defined as: 1) using the LOA, all observed agreements lie between 0.5 and 2.0 (perfect agreement $=1.0)(16) ; 2)$ the differences do not change over the range of means of the two scores (16); and 3) the mean score differences of the two methods are within \pm 1 SD formally assessed by the two onesided t-tests (17). While correlation approaches are not recommended in the validation studies $(18,19)$, Pearson correlation coefficients and the intraclass correlation coefficient (ICC) were also calculated to show comprehensive information on the relationship between the two dietary methods (20). All statistical analyses were performed using SAS version 9.4 (SAS Institute Inc., Cary, North Carolina, USA), and $\mathrm{p}<0.05$ was considered statistically significant.

\section{Results}

A total of nine heart and eight lung transplant recipients were randomly selected for the study and, 16 of the 17 patients agreed to participate (heart $n=8$, lung $\mathrm{n}=8$ ). Their average age was 55 years, $50 \%$ were women, average body mass index was $29 \mathrm{~kg} / \mathrm{m} 2$, virtually all patients were receiving anti-hypertensive and lipidlowering medications; and immunosuppressive therapy that included cyclosporine and prednisone therapy.

\section{Mediterranean diet}

The mean Mediterranean diet scores estimated from the short diet questionnaire and FFQ were very similar: 6.6 (SD 1.6) and 6.8 (SD 1.8), respectively and were significantly correlated (Pearson $\mathrm{r}=0.72, \mathrm{p}=0.002$ ). The ICC was 0.64 (95\% CI 0.31-0.85), and the observed mean bias 0.99 (SD 0.20; $\min 0.59$, $\max 1.38$ ) with $95 \%$ LOA 0.6 to 1.38 . The corresponding LOA plot showed no systematic bias in the variability across the range of the mean of the two methods (Figure 1). The two one sided t-test procedure showed these two methods were equivalent (equivalent region 0.50, $\mathrm{t}$-upper 6.08, $\mathrm{p}<0.001$; $\mathrm{t}$-lower $-3.04, \mathrm{p}=0.004$; overall $\mathrm{p}=0.004$ ). 


\section{Figure 1}

Bland-Altman plots The bias of the two methods (the ratio of scores from short dietary questionnaire to scores from FFQ) against the mean of the two methods [(the mean score of the short questionnaire) + (the mean score from the FFQ)/2]

a) Mediterranean diet: the mean bias (mean ratio) $=0.99$ (min 0.70, max 1.33) (lower LOA 0.59, upper LOA 1.38)

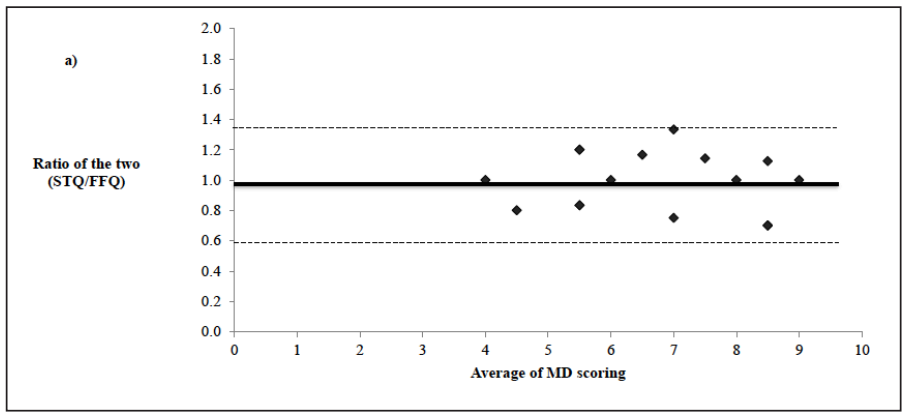

b) Low-fat diet: the mean bias (mean ratio) $=1.04$ (min 0.57, max 1.60) (lower LOA 0.43, upper LOA 1.64)

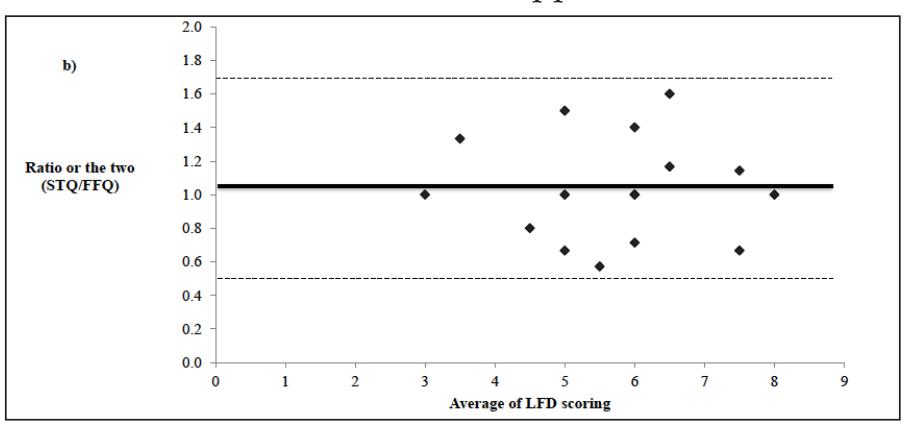

LFD: low-fat diet; LOA: limits of agreement; MD: Mediterranean diet; STQ: short questionnaire -------- Indicate upper and lower 95\% limits of agreement.

\section{Low-fat diet}

The mean score derived from the short low-fat dietary questionnaire and the corresponding score from the FFQ were also similar: 5.7 (SD 1.6) and 5.8 (SD 1.7), respectively. The Pearson correlation coefficient showed moderate agreement but was not statistically significant $(\mathrm{r}=0.42, \mathrm{p}=0.11)$. The ICC between the two methods was 0.44 (95\% CI 0.12-0.79) and mean bias was 1.04 (SD 0.31, $\min 0.57$, max 1.50). All observations were within $95 \%$ LOA (0.43-1.64), with no sign of variability across the range of the means (Figure 1). The two one sided t-tests showed the two methods were equivalent (equivalent region -0.06 , t-upper 3.93, $\mathrm{p}<0.001$; t-lower $-4.21, \mathrm{p}<0.001$; overall $\mathrm{p}<0.001)$.

\section{Discussion}

This study examined the relative validity of two short dietary questionnaires for Mediterranean and low-fat diets respectively, compared with a 183 item, semi-quantitative FFQ as the reference method among heart and lung transplant recipients. Overall, our results showed both short diet questionnaires performed adequately in comparison with the scores derived from the FFQ. Our results were made more robust by being based on multiple assessment methods (20).

While there was a statistically significant, good correlation between the short Mediterranean diet questionnaire and the FFQ, the correlation with the lowfat diet was only acceptable and not significant. However, the ICC showed a moderately good agreement for the low-fat diet and within the typically observed values in short dietary questionnaire validation studies (5). Mean biases calculated using Bland-Altman method were close to 1.00 for both short questionnaires, which indicates, on average, excellent agreement. However, calculated bias ranges for the low-fat diet were wider and thus less precise than those of the Mediterranean diet. All observed upper- and lower biases were within the predefined adequate range and the original validation study of the short Mediterranean diet questionnaire using a FFQ as a reference method among older Spanish adults also showed a similar range of biases (43\% under- and 53\% over-estimated compared with the reference method (6)). The Bland and Altman plot showed no systematic bias in either short questionnaire compared with the FFQ, and the results from the two one-sided t-tests showed the scores derived from short dietary questionnaires and FFQ to assess Mediterranean diet and low-fat diet were equivalent.

Correlation coefficients (Pearson, Spearman, and ICC) have been commonly employed methods in the method comparison studies (20). While correlation coefficients can provide extra information about the relationship between the two methods, the use of correlation in the validity studies have been criticized because their inability to assess agreement and bias adequately $(15,18)$. In contrast, LOA method is able to assess the magnitude of disagreement (mean bias) of two quantitative measurements and provide the agreement intervals (15). However, interpretation of the LOA approach is difficult and has been inconsistent: how wide the interval to be 'poor' or how narrow to be 'good' agreement. At least in the area of nutrition, previous studies using the LOA approach justified reasonable or good agreement by no priori definition or merely comparing other studies $(21,22)$. To overcome this issue, a few methods have suggested including the two one-sided t-test procedure used in this study (23). Although this procedure is not widely used to assess dietary intake method validation studies, it is likely to facilitate interpretation of the results from the widely used LOA method (23).

Short dietary questionnaires do not provide accurate intake level compared with more detailed dietary intake methods. However, short questionnaires can minimize the time required to complete and process the data and are therefore, highly cost effective. In addition, because short questionnaires do not require high cognitive ability or a long period of time to complete, this approach may 
Table 1

14-point Mediterranean dietary adherence questionnaire ${ }^{1}$

\begin{tabular}{|c|c|}
\hline Dietary habit/ consumption frequency & Response for 1 point ${ }^{2}$ \\
\hline 1. Do you use extra virgin olive oil as main culinary/cooking fat/oil? & Yes \\
\hline $\begin{array}{l}\text { 2. How much extra virgin olive oil do you eat in a given day (including oil used for cooking, salads, out-of-home meals } \\
\text { etc.)? }\end{array}$ & $\geq 4$ table spoons \\
\hline 3. How many vegetable servings do you eat per day? ( 1 serving $=200 \mathrm{~g}$; side dish as a half serving) & 2 or more (at least 1 serving raw or as salad) \\
\hline 4. How many fruit units (including natural fruit juices) do you eat per day? & $\geq 3$ \\
\hline 5. How many servings of red meat, beef-burger or meat products (ham, sausage, bacon etc.) do you eat per week? & $<1$ \\
\hline 6. How many servings of butter, margarine or cream do you eat per day? ( 1 serving = $12 \mathrm{~g}$ or 1 tablespoon) & $<1$ \\
\hline 7. How many sweetened and / or carbonated beverages do you drink per day? & $<1$ \\
\hline 8. How much red wine do you drink per week? & $\geq 7$ glasses \\
\hline 9. How many servings of legumes / pulses do you eat per week? ( 1 serving $=150 \mathrm{~g}$ or $1 / 2$ cup in dry form) & $\geq 3$ \\
\hline $\begin{array}{l}\text { 10. How many servings of fish or shellfish do you eat per week? ( } 1 \text { serving } 100-150 \mathrm{~g} \text { of fish [size of deck of cards] or } 4-5 \\
\text { units or } 200 \mathrm{~g} \text { of shellfish) }\end{array}$ & $\geq 3$ \\
\hline $\begin{array}{l}\text { 11. How many times per week do you eat desserts or pastries (not homemade), such as biscuits, cookies, cakes, custard } \\
\text { etc.? }\end{array}$ & $<3$ \\
\hline 12. How many servings of unsalted nuts (including peanuts) do you eat per week? ( 1 serving $=30 \mathrm{~g}$ or 1 small handful) & $\geq 3$ \\
\hline 13. Do you prefer to eat chicken, turkey or lean game instead of pork, beef-burger, sausage or bacon? & Yes \\
\hline $\begin{array}{l}\text { 14. How many times per week do you eat a self-made sauce (sofrito) prepared with tomato, garlic, onion or leeks - } \\
\text { simmered in olive oil. Used as a garnish to season vegetable, pasta or rice dishes? }\end{array}$ & $\geq 2$ \\
\hline
\end{tabular}

1. Adapted from Estruch et al. (7); 2. Criteria to score $=1$; otherwise score $=0$.

Table 2

9-point low fat diet adherence questionnaire ${ }^{1}$

\begin{tabular}{|c|c|c|c|}
\hline \multirow[t]{2}{*}{ Dietary habit/ consumption frequency } & \multicolumn{3}{|c|}{ Score } \\
\hline & 2 & 1 & 0 \\
\hline $\begin{array}{l}\text { 1. On average, how many tablespoons of vegetable oil (e.g. sunflower, olive, sesame, rapeseed oil) do you consume in a given day for } \\
\text { frying, salads \& out of house meals etc.? }\end{array}$ & $0-1$ & $2-4$ & $\geq 5$ \\
\hline $\begin{array}{l}\text { 2. Do you remove visible fat (or skin) from chicken, duck, pork, lamb or beef before cooking; and the fat from soups, broths and } \\
\text { cooked meat dishes before eating? }\end{array}$ & & Yes & No \\
\hline $\begin{array}{l}\text { 3. How many servings of non-lean meats, hamburger, commercial minced meat, sausage, cold meat, cured ham, bacon, salami or offal } \\
\text { do you consume per week? (meat serving }=100 \mathrm{~g} \text { or salami or bacon } 30 \mathrm{~g} \text { ) }\end{array}$ & $0-1$ & $2-4$ & $\geq 5$ \\
\hline $\begin{array}{l}\text { 4. How many servings of butter, margarine, lard, mayonnaise, milk-cream or milk-based ice cream do you consume per week? } \\
\text { (spread fat serving }=2 \mathrm{~g} \text {, ice cream }=100 \mathrm{~g} \text { ) }\end{array}$ & $0-1$ & $2-4$ & $\geq 5$ \\
\hline 5. Do you exclusively consume low-fat dairy products? & & Yes & No \\
\hline 6. How many times per week do you eat fried foods e.g. chips/French fries or fried chicken? & $0-1$ & $2-4$ & $\geq 5$ \\
\hline 7. How many times per week do you consume fatty fish or fish or seafood canned in oil? & $0-1$ & $2-4$ & $\geq 5$ \\
\hline $\begin{array}{l}\text { 8. How many servings of commercial sweets or industrial bakery products (not homemade), such as cakes, cookies, biscuits or } \\
\text { custard do you consume per week? (cake serving }=80 \mathrm{~g} \text { or } 6 \text { biscuits } 40 \mathrm{~g} \text { ) }\end{array}$ & $0-1$ & $2-4$ & $\geq 5$ \\
\hline 9. How many times per week do you consume nuts (including peanuts), potato, corn or wheat crisps or commercial snacks? & $0-1$ & $2-4$ & $\geq 5$ \\
\hline
\end{tabular}

1 Adapted from Estruch et al. (7)

also help increase participation in a study. Assessing these simpler, pragmatic dietary habits among organ transplant recipients is crucial as improved and targeted dietary advice can reduce or even obviate unnecessary clinical care. Dietary assessment using short questionnaires can assist in identifying who needs particular dietary advice in a timely manner than with previous methods.

Limitations of the study included the use of a fulllength FFQ as the reference method. While it was previously validated to assess usual dietary intake, FFQ is prone to bias and short dietary questionnaires have the similar biases with FFQ (9). In addition, this was a cross-sectional study, so it was unable to assess actual diet change or adherence to diet patterns over time. Third, although all participants completed the three dietary questionnaires, the sample size was small and therefore, estimates would be less precise and restricted the methods available to assess validity.. Our findings would only be generalizable to people who have similar 
characteristics to our participants. That is, heart or lung transplant adult recipients with at least one year posttransplantation. Nevertheless, despite its small size, our study is noteworthy in being the first to compare the agreement of short questionnaires and FFQ to assess a Mediterranean diet and a low-fat diet among lung and heart transplant recipients.

In conclusion, we demonstrate that diet habits to measure a Mediterranean diet or a low-fat diet using short dietary intake questionnaires and full-FFQ are comparable among transplant recipients. These short questionnaires are highly cost-effective tools for quickly identifying patients not adhering to dietary advice and addressing this in a timely manner.

Ethics Declaration: This research was carried out in accordance with the Declaration of Helsinki of the World Medical Association and received ethical approval from the NRES Committee North West.

Funding/Support Disclosure: KM was supported by the National Health and Medical Research Council of Australia Program Grant No. 552429 \& 1073898. TE was supported by the New Start Transplant Charity for PhD studentship.

Conflict of Interest Disclosures: The authors do not have any conflicts of interest.

\section{References}

1. Rees K, Hartley L, Flowers N, Clarke A, Hooper L, Thorogood M, Stranges S. 'Mediterranean' dietary pattern for the primary prevention of cardiovascular disease. The Cochrane database of systematic reviews 2013;8, Cd009825. doi:10.1002/14651858.CD009825.pub2.

2. Krauss RM, Eckel RH, Howard B, Appel LJ, Daniels SR, Deckelbaum RJ, Erdman JW, Kris-Etherton P, Goldberg IJ, Kotchen TA, Lichtenstein AH, Mitch WE, Mullis R, Robinson K, Wylie-Rosett J, St. Jeor S, Suttie J, Tribble DL, Bazzarre TL. AHA Dietary Guidelines: Revision 2000: A Statement for Healthcare Professionals From the Nutrition Committee of the American Heart Association. Circulation 2000;102, 2284-2299. doi:10.1161/01. cir.102.18.2284.

3. USDA. Nutrition and Your Health: Dietary Guidelines for American 2000. http:/ / health.gov/ dietaryguidelines/2000.asp

4. Zeltzer SM, Taylor DO, Tang WHW. Long-term dietary habits and interventions in solid-organ transplantation. J Heart Lung Transplant 2015;34, 1357-1365. doi:10.1016/j.healun.2015.06.014.

5. England CY, Andrews RC, Jago R, Thompson JL. A systematic review of brief dietary questionnaires suitable for clinical use in the prevention and management of obesity, cardiovascular disease and type 2 diabetes. Eur J Clin Nutr 2015;69, 977-1003. doi:10.1038/ ejcn.2015.6.

6. Schroder H, Fito M, Estruch R, Martinez-Gonzalez MA, Corella D, SalasSalvado J, Lamuela-Raventos R, Ros E, Salaverria I, Fiol M, Lapetra J, Vinyoles E, Gomez-Gracia E, Lahoz C, Serra-Majem L, Pinto X, RuizGutierrez V, Covas MI. A short screener is valid for assessing Mediterranean diet adherence among older Spanish men and women. J Nutr 2011;141, 11401145. doi:10.3945/jn.110.135566.

7. Estruch R, Ros E, Salas-Salvadó J, Covas M-I, Corella D, Arós F, GómezGracia E, Ruiz-Gutiérrez V, Fiol M, Lapetra J, Lamuela-Raventos RM,
Serra-Majem L, Pintó X, Basora J, Muñoz MA, Sorlí JV, Martínez JA, Martínez-González MA. Primary prevention of cardiovascular disease with a Mediterranean diet. N Engl J Med 2013;368, 1279-1290. doi:10.1056/ NEJMoa1200303.

8. Thompson FE, Midthune D, Williams GC, Yaroch AL, Hurley TG, Resnicow K, Hebert JR, Toobert DJ, Greene GW, Peterson K, Nebeling L. Evaluation of a short dietary assessment instrument for percentage energy from fat in an intervention study. J Nutr 2008;138, 193s-199s.

9. Thompson FE, Byers T. Dietary assessment resource manual. J Nutr 1994;124 2245s-2317s.

10. Estruch R, Martínez-González MA, Corella D, Salas-Salvadó J, Ruiz-Gutiérrez V, Covas MI, Fiol M, Gómez-Gracia E, López-Sabater MC, Vinyoles E, Arós F, Conde M, Lahoz C, Lapetra J, Séez G, Ros E. Effects of a Mediterraneanstyle diet on cardiovascular risk factors. Ann Intern Med 2006;145, 1-W4. doi:10.7326/0003-4819-145-1-200607040-00004.

11. Marks GC, Hughes MC, van der Pols JC. The effect of personal characteristics on the validity of nutrient intake estimates using a food-frequency questionnaire. Public Health Nutr 2006;9, 394-402. doi:http://dx.doi. org / 10.1079/PHN2005839.

12. Marks GC, Hughes MC, van der Pols JC. Relative validity of food intake estimates using a food frequency questionnaire is associated with sex, age, and other personal characteristics. J Nutr 2006;136, 459-465.

13. Ibiebele TI, Parekh S, Mallitt K-a, Hughes MC, O'Rourke PK, Webb PM. Reproducibility of food and nutrient intake estimates using a semiquantitative FFQ in Australian adults. Public Health Nutr 2009;12, 2359-2365. doi:10.1017/S1368980009005023.

14. Wallingford SC, Pilkington SM, Massey KA, Al-Aasswad NMI, Ibiebele TI, Celia Hughes M, Bennett S, Nicolaou A, Rhodes LE, Green AC. Threeway assessment of long-chain n-3 PUFA nutrition: by questionnaire and matched blood and skin samples. Br J Nutr 2013;109, 701-708. doi:10.1017/ S0007114512001997.

15. Bland JM, Altman DG. Measuring agreement in method comparison studies. Stat Methods Med Res 1999;8, 135-160. doi: 10.1177/096228029900800204

16. Ambrosini GL, van Roosbroeck SA, Mackerras D, Fritschi L, de Klerk NH Musk AW. The reliability of ten-year dietary recall: implications for cancer research. J Nutr 2003;133, 2663-2668.

17. Schuirmann DJ. A comparison of the two one-sided tests procedure and the power approach for assessing the equivalence of average bioavailability. J Pharmacokinet Biopharm 1987;15, 657-680. doi: 10.1007/BF01068419.

18. Bland JM, Altman DG. A note on the use of the intraclass correlation coefficient in the evaluation of agreement between two methods of measurement. Comput Biol Med 1990;20, 337-340.

19. Hebert JR, Miller DR. The inappropriateness of conventional use of the correlation coefficient in assessing validity and reliability of dietary assessment methods. Eur J Epidemiol 1991;7, 339-343.

20. Lombard MJ, Steyn NP, Charlton KE, Senekal M. Application and interpretation of multiple statistical tests to evaluate validity of dietary intake assessment methods. Nutr J 2015;14:40. 10.1186/s12937-015-0027-y.

21. Fernandez-Ballart JD, Pinol JL, Zazpe I, Corella D, Carrasco P, Toledo E, Perez-Bauer M, Martinez-Gonzalez MA, Salas-Salvado J, Martin-Moreno JM Relative validity of a semi-quantitative food-frequency questionnaire in an elderly Mediterranean population of Spain. Br J Nutr 2010;103, 1808-1816. 10.1017 / s0007114509993837.

22. Villegas R, Yang G, Liu D, Xiang YB, Cai H, Zheng W, Shu XO. Validity and reproducibility of the food-frequency questionnaire used in the Shanghai men's health study. Br J Nutr 2007;97, 993-1000. 10.1017/s0007114507669189.

23. Batterham MJ, Van Loo C, Charlton KE, Cliff DP, Okely AD. Improved interpretation of studies comparing methods of dietary assessment: combining equivalence testing with the limits of agreement. Br J Nutr 2016;115, 1273-1280. doi:10.1017/S0007114516000040. 